\title{
Self-assembly of inner skin hollow fiber polyelectrolyte multilayer membranes by a dynamic negative pressure layer-by-layer technique
}

\author{
Guojun Zhang a , Xue Song ${ }^{\mathrm{a}}$, Shulan Ji ${ }^{\mathrm{a}, *}$, Naixin Wang ${ }^{\mathrm{a}}$, Zhongzhou Liu ${ }^{\mathrm{b}}$ \\ a Center for Membrane Technology, College of Environmental and Energy Engineering, Beijing University of Technology, Beijing 100124, PR China \\ ${ }^{\mathrm{b}}$ Research Center for Eco-Environmental Sciences, Chinese Academy of Sciences, Beijing 100085, PR China
}

\section{A R T I C L E I N F O}

\section{Article history:}

Received 26 May 2008

Received in revised form 2 July 2008

Accepted 4 July 2008

Available online 16 July 2008

\section{Keywords:}

Hollow fiber

Polyelectrolyte multilayer membranes

Dynamic negative pressure layer-by-layer process

Pervaporation

\begin{abstract}
A B S T R A C T
In the past studies, electrostatic layer-by-layer (LbL) adsorption of oppositely charged polyelectrolytes has proven to be a promising method for the preparation of polyelectrolyte multilayer membranes (PEMMs). Till now, this method was mainly used to assemble flat sheet and tubular membranes. Since hollow fiber membrane has some advantages such as high-packing density, self-contained mechanical support and hence the consequent economical superiority, this study therefore seeked to assemble inner skin hollow fiber PEMMs by using a dynamic LbL adsorption technique. The assembly process was successfully accomplished by alternatively dynamically filtrating polyacrylic acid (PAA) and polyethyleneimine (PEI) on a hydrolyzed hollow fiber polyacrylonitrile (PAN) membrane under a negative pressure condition. In the case of pervaporation separation of $95 \mathrm{wt} . \%$ ethanol-water mixture $\left(50^{\circ} \mathrm{C}\right)$, the membrane obtained with only 4.5 and 6.5 bilayers had separation factor of 245 and 1338 while the permeate fluxes were 290 and $120 \mathrm{~g} /\left(\mathrm{m}^{2} \mathrm{~h}\right)$, respectively. The pervaporation separation behavior of various alcohol/water mixtures with the alcohols being $t$-butanol, 2-propanol and ethanol were also investigated. Finally, scanning electron microscopy and atomic force microscopy clearly confirms a uniform and defect-free layer formed on the inner surface of hollow fiber support. Since different polyelectrolyte pairs could be used to assemble PEMMs for different uses, it was expected that the dynamic negative pressure LbL adsorption technique could also potentially be used to prepare many types of PEMMs in other fields.
\end{abstract}

(c) 2008 Elsevier B.V. All rights reserved.

\section{Introduction}

Pervaporation is widely recognized as an energy-efficient and prospective industrial process for the separation of a wide variety of liquid mixtures such as azeotropic, close-boiling point, isomers and/or heat sensitive mixtures [1-5]. Pervaporation has been commercialized for the dehydration of organic solvents. However, development of cost-effective membrane modules still remains a major issue. Currently, the plate-and-frame is the dominating module configuration employed in pervaporation. Compared with the plate-and-frame module, hollow fiber has some advantageous such as high-packing density, a self-contained mechanical support, a self-contained vacuum channel and hence the consequent economical superiority. A number of studies have contributed to the progress in developing such a promising pervaporation module [4-7]. However, it is challenging to directly fabricate asymmetric hollow fiber membranes with an ultra-thin defect-free selective layer which have superior pervaporation performance, meanwhile

\footnotetext{
* Corresponding author. Tel.: +86 1067392961 ; fax: +86 1067391983 .

E-mail address: jshl@bjut.edu.cn (S. Ji).
}

possess the ability to overcome the solvent-induced swelling [5]. Therefore, in addition to the direct fabrication with superior polymeric materials, preparation of hollow fiber composite membranes might be an effective alternative to achieve ultra-thin defect-free selective layer for pervaporation separation processes.

In recent years, there is increasing application of layer-bylayer (LbL) adsorption technique in the assembly of polyelectrolyte multilayer membranes (PEMMs) for pervaporation separation of solvent and water mixtures [8-12]. In order to optimize the assembly conditions and understand the membrane structure, the flat sheet membranes have always been the focus in most of the previous studies. Recently, the oppositely charged polyelectrolytes were deposited on the tubular support by LbL in laboratories. For example, Chen et al. prepared an inorganic-inorganic composite membrane by means of electrostatic self-assembly of polyelectrolytes on silica sol-gel modified tubular $\mathrm{ZrO}_{2} / \mathrm{Al}_{2} \mathrm{O}_{3}$ supports [13]. However, none work has dealt with the self-assembly of hollow fiber pervaporation membranes with LbL adsorption method. Considering that LbL adsorption is a time-consuming process, we have developed the dynamic LbL adsorption technique to reduce the deposition cycles [14,15]. More recently, an electric field-enhanced method was developed to enhance the assembly of polyelec- 
trolyte composite membranes by inducing an electric field during electrostatic adsorption process [16]. Our previous studies have demonstrated that the reduction in the cycles of polyelectrolyte deposition can be achieved while still retaining a very good selectivity by combining the layer-by-layer electrostatic force with a certain external force [14-16]. Another key problem regarding hollow fiber pervaporation membrane is to reasonably arrange vacuum channel. In the previous studies, a feed was commonly supplied from the shell side while vacuum was applied on the lumen side [3-6]. Few works have dealt with the preparation of inner skin hollow fiber pervaporation membranes as it has some difficulties in forming inner separation layer with conventional dip coating method. However, as an effective pervaporation module, the inner skin hollow fiber may offer some advantages over the outer skin module such as easily protection of the defect-free separation layer, good distribution of feed solution and low-transport resistance in the permeate side.

In this paper, we attempted to prepare the inner skin hollow fiber pervaporation membranes. Based on the past successful experiences in the assembly of flat sheet PEMMs with dynamic LbL technique, we propose to prepare hollow fiber composite membrane for pervaporation separation. The assembly principle is shown in Fig. 1. As shown in Fig. 1, hollow fiber PAN support membrane was firstly hydrolyzed with alkaline solutions to form a polyanion functional group. It was expected that the polyelectrolyte selective layer could be formed on the inner skin of hollow fiber by ionic bonds between the support membrane and the polyelectrolyte pairs deposited, which could be enhanced by alternatively filtrating polycation and polyanion solutions under a negative pressure. The pervaporation separation behavior of hollow fiber membranes with the alcohols being $t$-butanol, 2-propanol and ethanol are investigated with a relatively wide range of feed temperature and concentration. The micrographs of the hollow fiber polyelectrolyte multilayer membranes assembled by a dynamic LbL process were observed by using a scanning electron microscopy and an atomic force microscopy.

\section{Experimental}

\subsection{Materials}

The PAA powder having average molecular weight of 4,000,000 was obtained from Aldrich. Branched poly(ethyleneimine) (PEI) with the molecular weight of 60,000 was purchased from ACROS. Sodium hydroxide, $t$-butanol, 2-propanol and ethanol and were provided by Beijing Chemical Factory. Poly(ethylene glycol)s (PEGs) having the molecular weight of $6000,10,000,20,000$ were also supplied by Beijing Chemical Factory.

\subsection{Hollow fiber support membrane}

The hollow fiber support membranes used in this study were produced by the phase inversion method from polyacrylonitrile (PAN) polymer in our workshop [17]. The inner diameter of each hollow fiber was $1.1 \mathrm{~mm}$. The PAN fibers with an effective length of $15 \mathrm{~cm}$ were hydrolyzed by immersing into the aqueous solutions of sodium hydroxide. The hydrolysis tests were conducted in a water bath so that temperature can be manipulated to pre-determined levels. After hydrolyzing for $15 \mathrm{~min}$, the membranes was taken out and rinsed with de-ionized water until the $\mathrm{pH}$ values of the rinsed water reached about 7.0. These fibers were then put into an organic glass tube with a diameter of $1.5 \mathrm{~cm}$. Both ends of the module were sealed with epoxy resin. After $24 \mathrm{~h}$ for the epoxy to get cured, the small modules were mounted on the dynamic filtration system for assembly. The packing density of the hollow fiber membrane module tested was about $150 \mathrm{~m}^{2} / \mathrm{m}^{3}$.

\subsection{Polyelectrolyte multilayer membrane preparation by dynamic LbL process}

As shown in Fig. 2, the preparation of polyelectrolyte multilayer membranes was carried out by using a laboratory fabricated crossflow filtration cell. The polyanion and polycation solutions were alternatively provided into the inner channel of hollow fiber and then recycled by using two peristaltic pumps and through separate tubings. On the shell side, a vacuum pump was used to form a negative pressure. The PEMMs were assembled by filtrating the polyanion and polycation alternatively during a pre-determined period of filtration. The following steps were orderly carried out (a) PEI solution was pumped into the modules and recycled along the inner surface. Since the shell side was provided with a negative pressure of $-0.04 \mathrm{MPa}$ by a vacuum pump, the PEI solution was filtrated for $30 \mathrm{~min}$. (b) The membrane was rinsed with deionized water for twice. In order to remove the water remained on the inner surface of hollow fibers, nitrogen gas was put into the inner channels by a nitrogen cylinder. After that, the membrane was dried in an oven at $50^{\circ} \mathrm{C}$ for a pre-determined period. (c) PAA solution was recycled along the inner channel and filtrated under a negative pressure of $-0.04 \mathrm{MPa}$ for $30 \mathrm{~min}$. (d) The same way as (b). Steps (a)-(d) were repeated up to the pre-determined times. Upon the formation of PEMMs, they were stored for pervaporation experiments.

\subsection{Pervaporation experiments}

The hollow-fiber module for pervaporation test consisted of two fibers with effective lengths of $10 \mathrm{~cm}$ and effective area of $69.1 \mathrm{~cm}^{2}$. The hollow fibers modules were mounted onto a laboratory fabricated pervaporation system with lumen side as the feed side and shell side as the permeate side. Three modules with same fabrication and modification conditions were examined for each pervaporation condition. The permeate vapor was trapped with liquid nitrogen. The experiments were carried out at a down-stream pressure of 100 Pa by a vacuum pump. Fluxes were determined by measuring the weight of liquid collected in the cold traps during a certain time under steady-state conditions. The composition of the collected permeate was determined by gas chromatography (GC14C, SHIMADZU). The separation factor was calculated from the quotient of the weight ratio of water and alcohol in the permeate, $Y_{\mathrm{HOH}} / Y_{\mathrm{ROH}}$, and in the feed, $X_{\mathrm{HOH}} / X_{\mathrm{ROH}}$ :

$\alpha=\frac{Y_{\mathrm{HOH}} / Y_{\mathrm{ROH}}}{X_{\mathrm{HOH}} / X_{\mathrm{ROH}}}$

\subsection{TOC, FESEM and AFM experiments}

A total organic carbon (TOC) analyzer (TOC-V $\mathrm{V}_{\mathrm{CPH}}$, SHIMADZU) was used to determine the TOC values of PEG solutions before and after ultrafiltration using hollow support membrane before and after hydrolysis. A scanning electron microscopy (SEM) (Hitachi4700 , Japan) was used to observe the top surface and cross-section of the polyelectrolyte multilayer membranes obtained. All membrane samples were dried under vacuum, fractured in liquid nitrogen and gold-coated before observation. Surface topography was also performed in tapping mode by an atomic force microscopy (AFM) (Pico Scan ${ }^{\mathrm{TM}} 2500$, USA). Before AFM tests, the hollow fibers were cut longitudinally by means of a sharp razor blade. A small piece was put in-between two clean microscope slides and was made in flat under a slight pressure. The samples were then fixed 

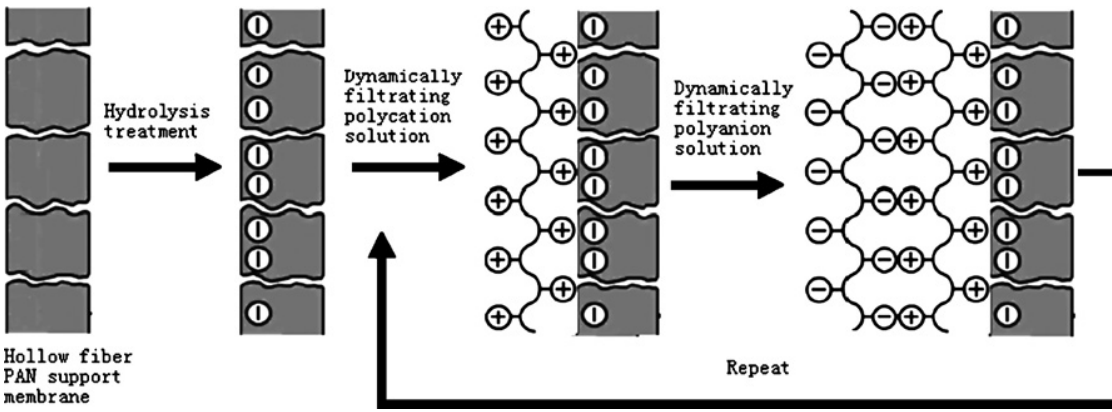

Fig. 1. Principles of self-assembly of PEMMs with dynamic negative pressure LbL process [9].

over disks by using double side adhesive tape. The laser beam of the AFM was focused on the preselected spot of the surface prior to the engagement of the cantilever. The membrane roughness parameters were therefore determined.

\section{Results and discussion}

\subsection{Characteristics of inner skin hollow fiber support membranes}

In order to assemble the polyelectrolyte layer onto the inner surface of hollow fibers, the inner skin support membranes were firstly spun by a dry/wet-phase inversion method in our workshop [17]. Subsequently, a charged inner surface was obtained based on the conversion of $-\mathrm{CN}$ groups on the PAN membrane surface into carboxyl groups under an alkaline condition. Therefore, the fibers were tailor-made for a suitable length and then immersed into the aqueous solutions of sodium hydroxide for hydrolysis. The resulting hollow fiber PAN membranes before and after hydrolysis were characterized in terms of morphology, permeability and retention capacity. The cross-sectional morphology of the prepared PAN hollow fiber examined by SEM is shown in Fig. 3. It could be seen that a highly asymmetric structure was formed in the hollow fiber membrane wall. As illustrated in Fig. 3(b), the hollow fiber was composed of an inner dense layer and an outer porous layer that exhibits a finger-like structure. For such an asymmetric membrane, the porous supporting layer generally provides negligible resistance, and the permeation process is mainly controlled by the inner skin layer. However, this membrane cannot be directly used for a pervaporation separation. Pervaporation is a process that separates liquid molecules with diameters in angstrom scale $(\AA)$. The mass transport across the pervaporation membranes is governed by a solution-diffusion mechanism [1]. This requires the membrane to be non-porous. As a comparison, a number of large pores of support membrane surface were clearly observed from Fig. 3(d). Therefore, the subsequent assembly of polyelectrolyte pairs was necessary to

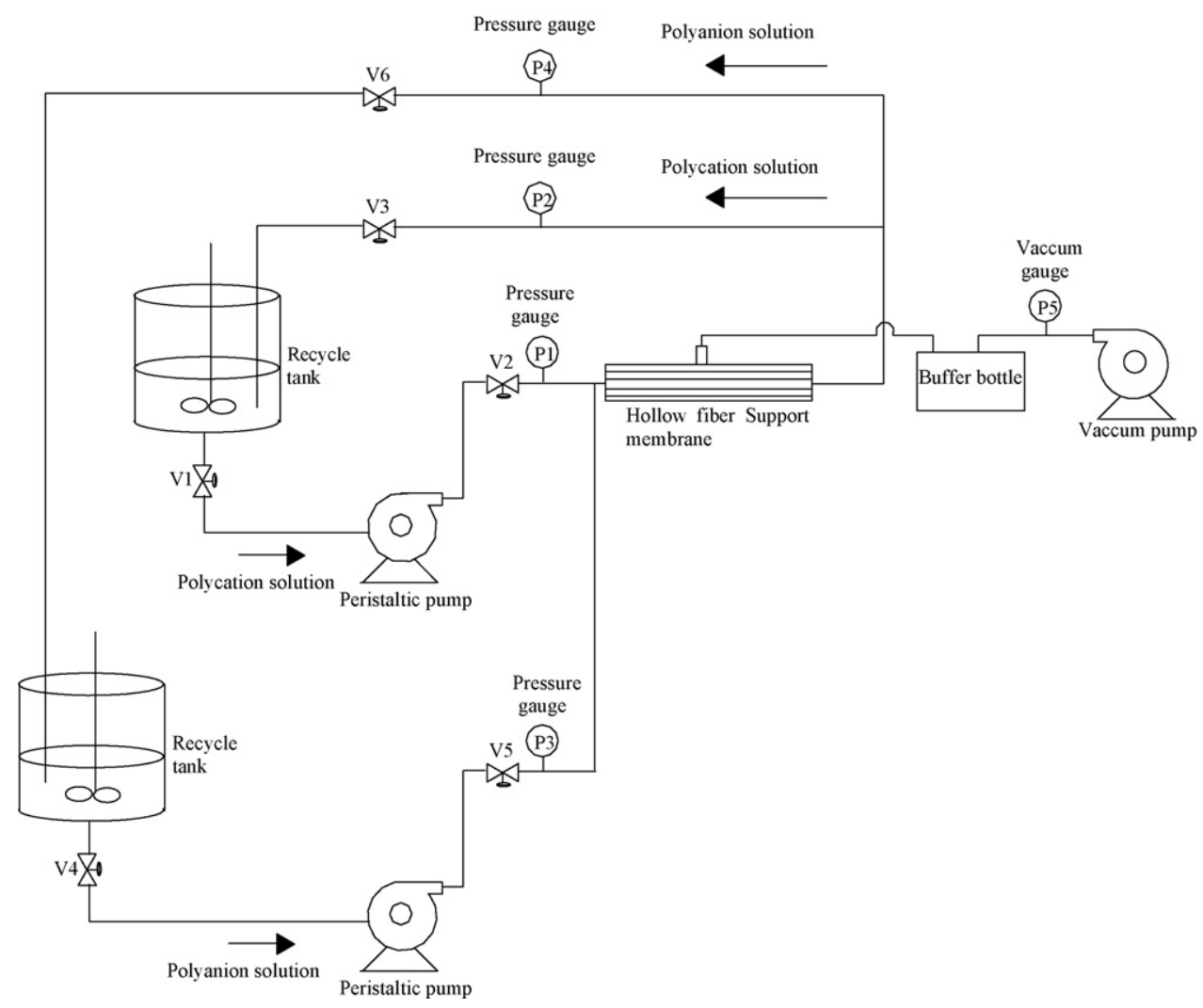

Fig. 2. Experimental apparatus for preparation of hollow fiber PEMMs by a dynamic negative pressure LbL adsorption technique. 
(a)

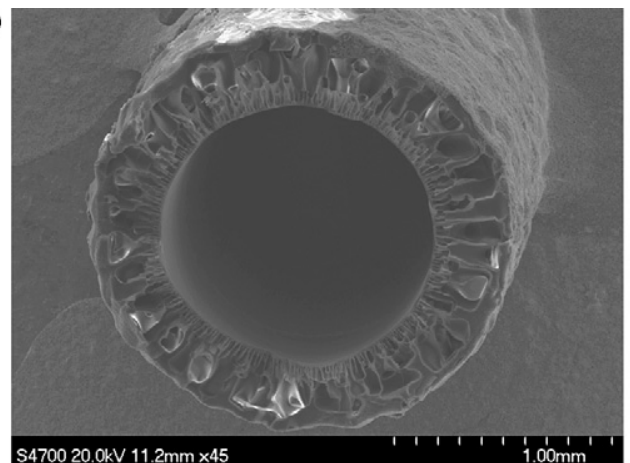

(c)

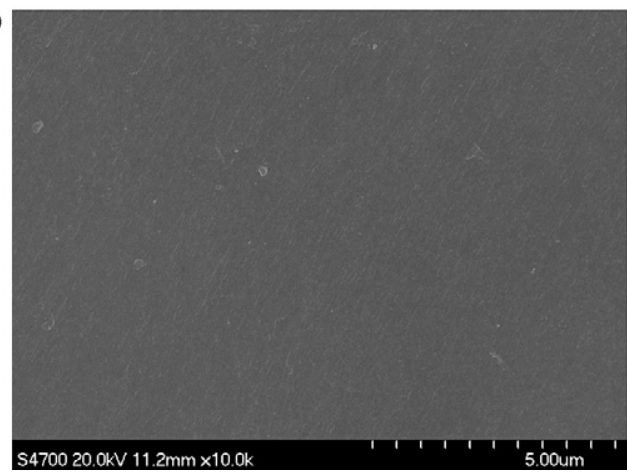

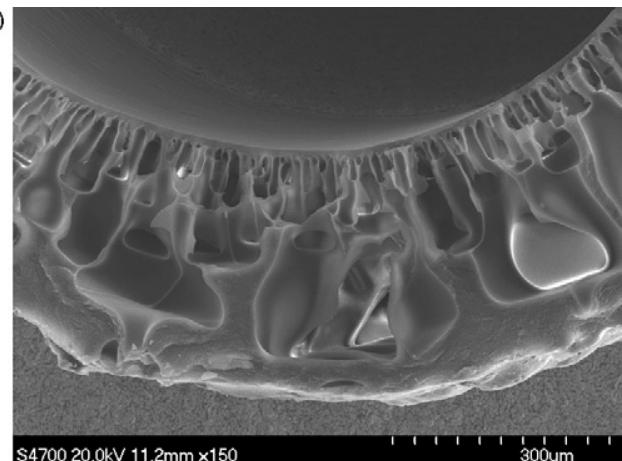

(d)

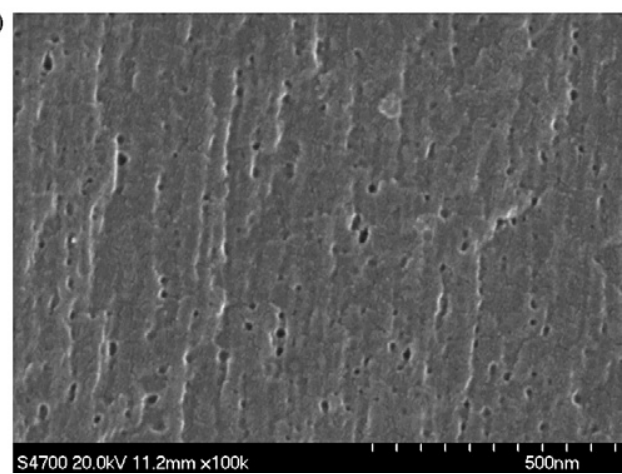

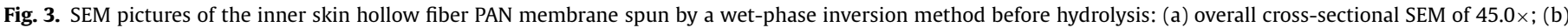
cross-sectional SEM of $150.0 \times$; (c) inner surface SEM (10.0k $\times$ ); (d) inner surface SEM (100.0k $\times$ ).

seal the pores and in turn to form a hydrophilic dense separation layer for dehydration of alcohols.

Additionally, in view of the fact that exceeding hydrolysis would reduce the mechanical strength of PAN membranes and increase the opportunity for big defects formation on membrane surfaces, compared to our previous study on flat sheet membrane [15], much milder hydrolysis conditions of $2 \mathrm{~N} \mathrm{NaOH}$ at $60^{\circ} \mathrm{C}$ for a period of 15 min were selected in this study. Table 1 summarizes the membrane performance before and after hydrolysis. As shown in Table 1, after a 15-min hydrolysis, membrane flux decreased from 160 to $82 \mathrm{l} /\left(\mathrm{m}^{2} \mathrm{~h}\right)$ while the retention increased for three PEGs with different molecular weight. This suggested the hydrolyzed PAN UF membrane became more compact and denser after hydrolysis. Meanwhile, the formation of a polyelectrolyte layer (carboxylic acid salts) which swells more readily in water than the virgin membrane may also lead to the flux declination and retention enhancement.

\subsection{Effects of bilayer number}

The pervaporation performances with different PEI/PAA numbers are shown in Fig. 4. It was noted increasing number of deposited PEI/PAA bilayers would lead to the increase of the water content of the permeate. For example, the water content of the permeate was only $9 \mathrm{wt}$.\% for one PEI layer deposited. However, the water content of the permeate quickly reached $80.7 \mathrm{wt} . \%(\alpha=33.9)$,

Table 1

Comparisons of PAN membrane performance before and after hydrolysis

\begin{tabular}{lrlll}
\hline Membrane & Flux $\left(1 /\left(\mathrm{m}^{2} \mathrm{~h}\right)\right)$ & \multicolumn{4}{l}{ Retention ratio (\%) } \\
\cline { 3 - 5 } & & PEG 20,000 & PEG 10,000 & PEG 6000 \\
\hline Before hydrolysis & 160 & 85.78 & 50.59 & 16.85 \\
After hydrolysis & 82 & 92.23 & 83.99 & 46.75
\end{tabular}

Hydrolysis conditions for PAN support membrane: $2 \mathrm{~N} \mathrm{NaOH}$, hydrolysis temperature: $60^{\circ} \mathrm{C}$, hydrolysis time: $15 \mathrm{~min}$, measurement pressure: $0.05 \mathrm{MPa}$.
84.6 wt.\% $(\alpha=104)$ and $92.8 \mathrm{wt} . \%(\alpha=245)$ for $2.5,3.5$ and 4.5 bilayers, respectively. These values continuously increased to $96.4 \mathrm{wt} . \%$ ( $\alpha=509)$ and $98.6 \mathrm{wt} . \%(\alpha=1338)$ as the bilayer number increased to 5.5 and 6.5. Simultaneously, the total flux decreases from about $23,444 \mathrm{~g} /\left(\mathrm{m}^{2} \mathrm{~h}\right)$ to about $290 \mathrm{~g} /\left(\mathrm{m}^{2} \mathrm{~h}\right)$ for the 4.5 bilayer sample, and to $120 \mathrm{~g} /\left(\mathrm{m}^{2} \mathrm{~h}\right)$ for 6.5 bilayers. Obviously, the inner skin layer became denser and more compact with the increase in the deposition cycles of polyelectrolyte pairs. It was concluded that the adsorption of at least 4.5 polyelectrolyte bilayers on the hollow fiber PAN support was necessary to get a competitive separation capability separation. As a comparison, the water content of the permeate

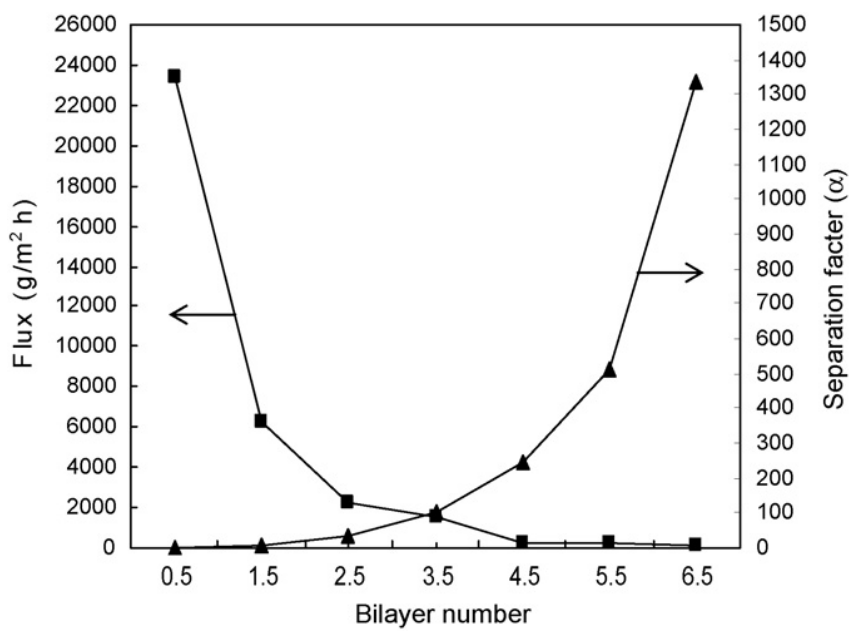

Fig. 4. Effect of polyion bilayer numbers on separation factor and flux (hydrolysis conditions for PAN support membrane: hydrolysis temperature: $60^{\circ} \mathrm{C}$, hydrolysis time: $15 \mathrm{~min}$; preparative conditions: negative pressure $=-0.04 \mathrm{MPa}, 30 \mathrm{~min}$ filtration time, PAA molecular weight 4000,000, [PAA] $=0.05 \mathrm{wt} . \%,[\mathrm{PEI}]=0.25 \mathrm{wt} . \%$; pervaporation conditions: feed temperature $50^{\circ} \mathrm{C}$, permeate pressure $100 \mathrm{~Pa}$, EtOH content in feed solution $95 \mathrm{wt} . \%$ ). 


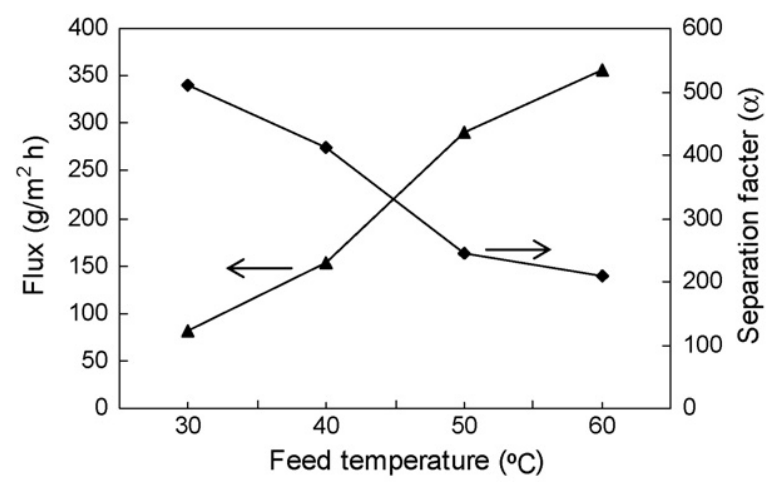

Fig. 5. Effect of feed temperature on pervaporation performance (hydrolysis conditions for PAN support membrane: hydrolysis temperature: $60^{\circ} \mathrm{C}$, hydrolysis time: 15 min; preparative conditions: 4.5 bilayers, dynamic negative pressure: $-0.04 \mathrm{MPa}$, $30 \mathrm{~min}$ filtration time, $0.05 \mathrm{wt}$ \% PAA aqueous solution, $0.25 \mathrm{wt} . \%$ aqueous PEI solution, $25^{\circ} \mathrm{C}$; pervaporation conditions: feed temperature $50^{\circ} \mathrm{C}$, down-stream pressure $100 \mathrm{~Pa}$ ).

was only $23.5 \%$ while the permeate flux was $6556 \mathrm{~g} /\left(\mathrm{m}^{2} \mathrm{~h}\right)$ for the control samples of PEMMs assembled by static LbL adsorption with 4.5 bilayers without negative pressure. This clearly suggested that the LbL assembly could be enhanced by combining the electrostatic adsorption force with external force.

\subsection{Alcohol/water pervaporation}

In order to evaluate the hollow fiber PEMMs assembled by dynamic negative pressure LbL adsorption, permeate flux and water content in permeate were measured within relatively wide ranges

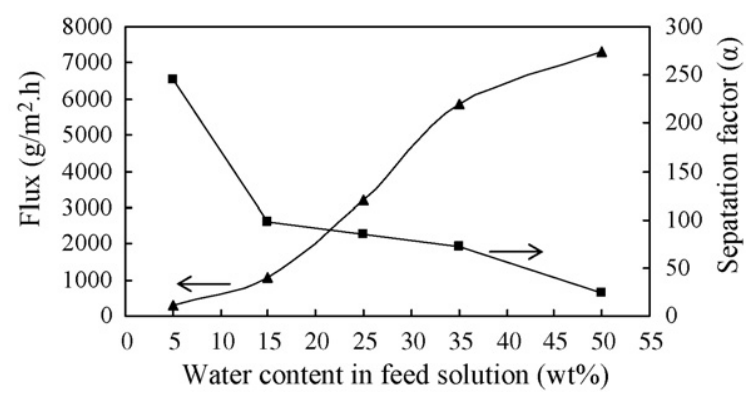

Fig. 6. Effect of water content in feed solution on pervaporation performance (hydrolysis conditions for PAN support membrane: hydrolysis temperature: $60{ }^{\circ} \mathrm{C}$, hydrolysis time: $15 \mathrm{~min}$; preparative conditions: 4.5 bilayers, dynamic negative pressure: $-0.04 \mathrm{MPa}, 30 \mathrm{~min}$ filtration time, $0.05 \mathrm{wt} . \%$ PAA aqueous solution, $0.25 \mathrm{wt} . \%$ aqueous PEI solution, $25^{\circ} \mathrm{C}$; pervaporation conditions: feed temperature $50^{\circ} \mathrm{C}$, down-stream pressure $100 \mathrm{~Pa}$ ).

of feed temperature and water content in feed solution. It was noted from Fig. 5 that permeate flux increased with the increase in operating temperature due to the increases in the water vapor pressure of feed side and the diffusion coefficients. Therefore, increasing the pervaporation temperature is quite often useful in order to improve the flux of a membrane. However, it was also found that the selectivity decreased with the increase in the feed temperature for hollow fiber PEMMs. The water and alcohol partial fluxes were calculated based on total flux and selectivity and are shown in Table 2. Table 2 proved that both water flux and alcohol flux increased with the increase in feed temperature. However, the alcohol flux increased much more rapidly than water flux did, which lead to the decline of selectivity with the increase in feed temperature. Fig. 6 shows (a)

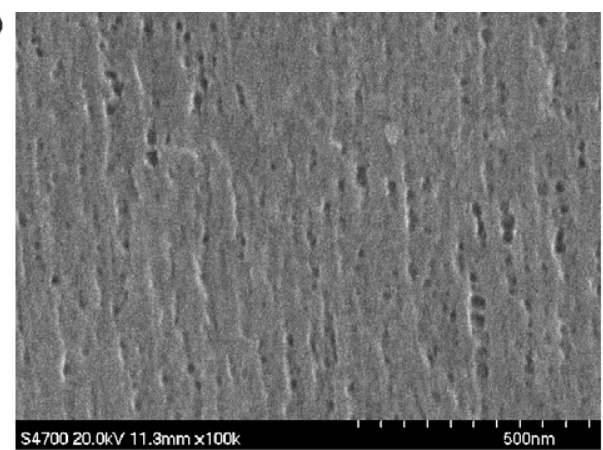

(c)

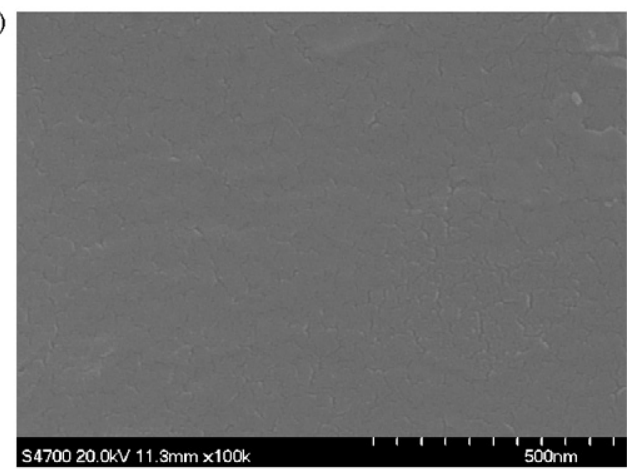

(b)

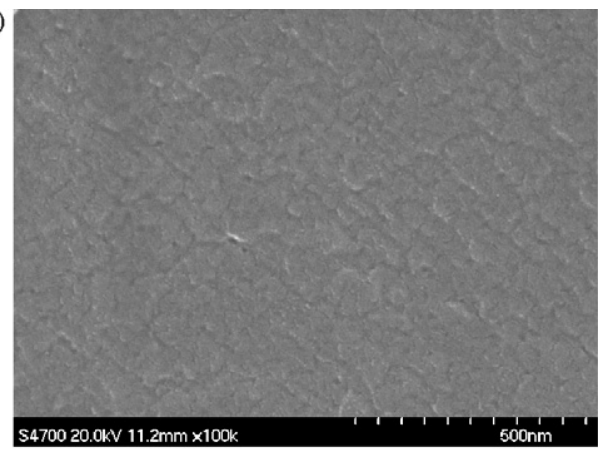

(d)

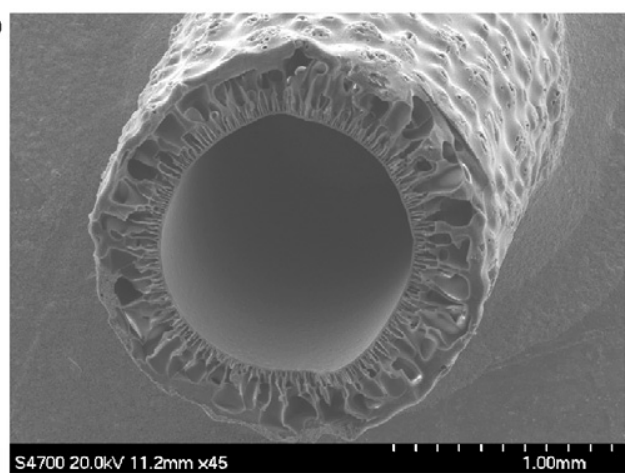

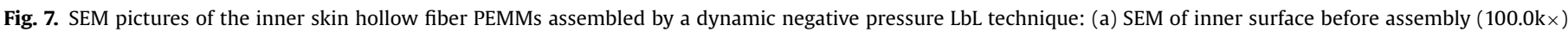

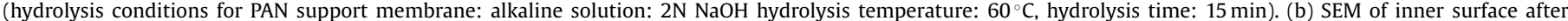

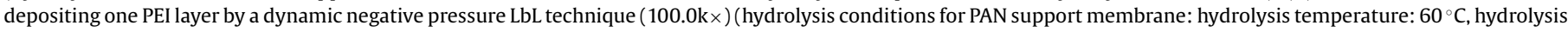

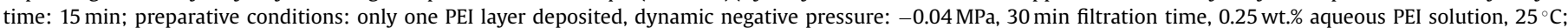

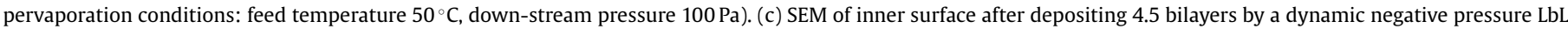

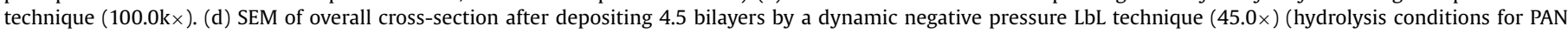

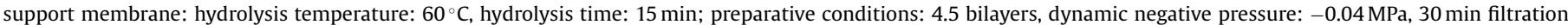
time, 0.05 wt.\% PAA aqueous solution, 0.25 wt. $\%$ aqueous PEI solution, $25^{\circ} \mathrm{C}$; pervaporation conditions: feed temperature $50{ }^{\circ} \mathrm{C}$, down-stream pressure $100 \mathrm{~Pa}$ ). 
(a) Image: '6010', Topograph, 0.00[V] Bias, right-left

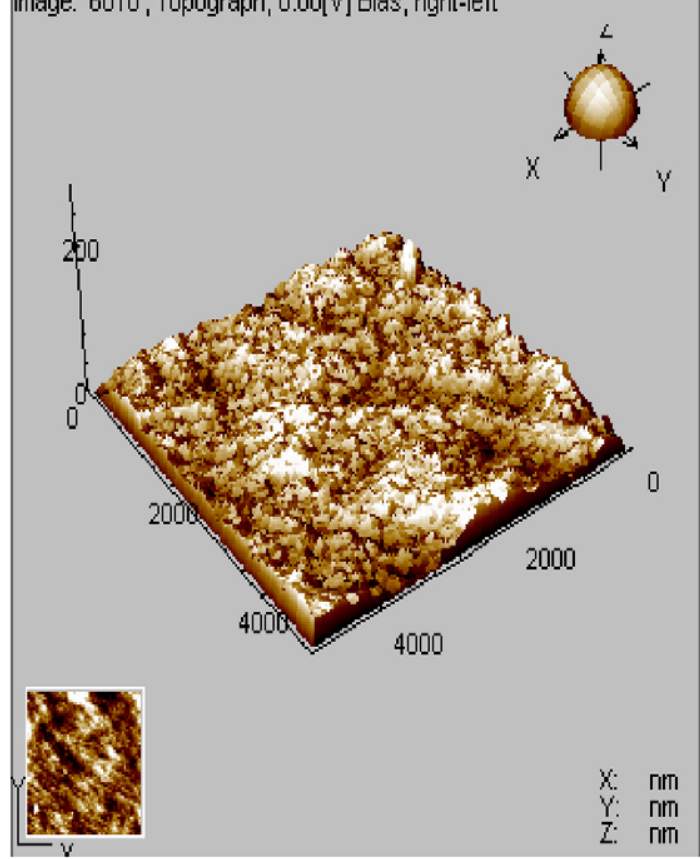

(c) Image: '8005', Topograph, 0.00[V] Bias, right-lett

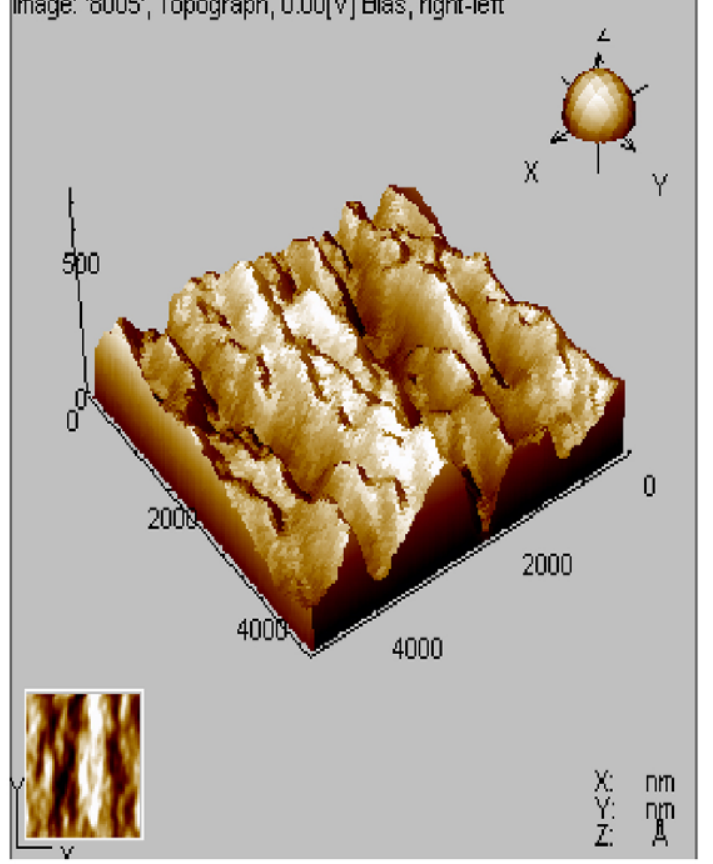

(b) |lmage: '7007', Topograph, 0.000[V] Bias, lett-right

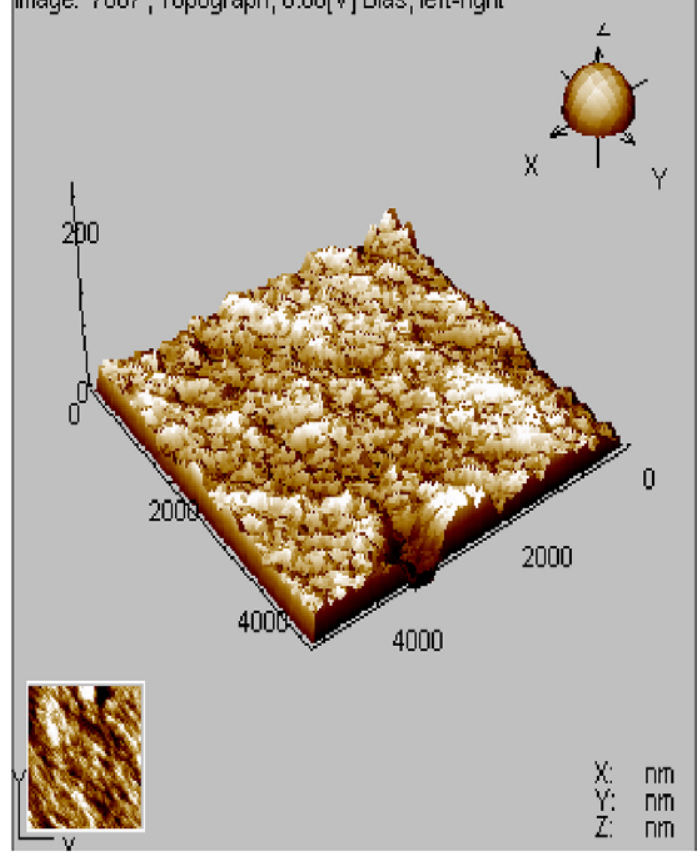

(d) Image: '9004', Topograph, 0.00[V] Bias, lett-right

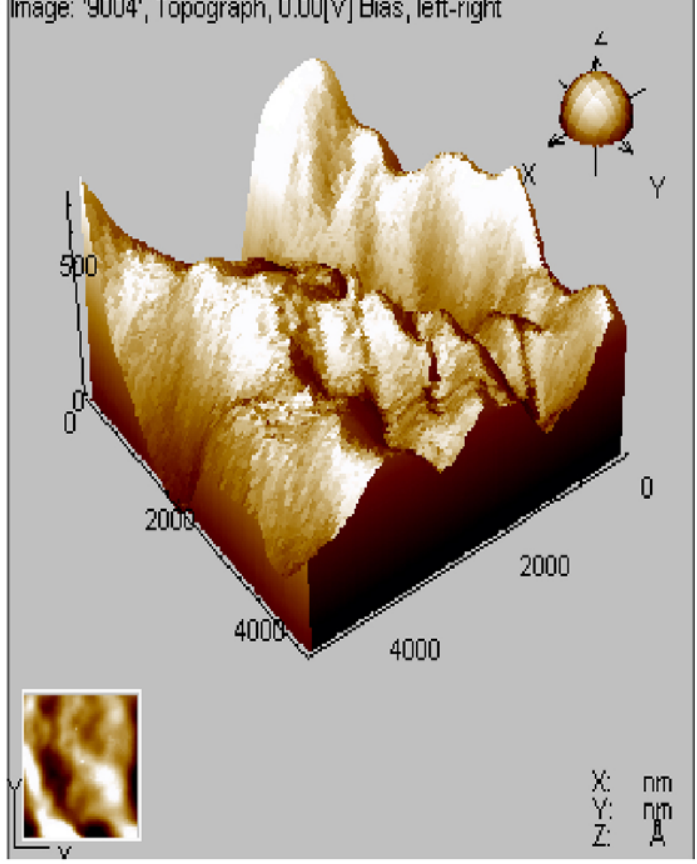

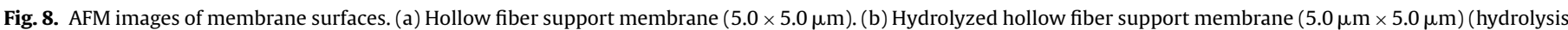
conditions for PAN support membrane: hydrolysis temperature: $60^{\circ} \mathrm{C}$, hydrolysis time: $15 \mathrm{~min}$ ). (c) Hollow fiber PEMM assembled by dynamic negative pressure LbL technique $(5.0 \mu \mathrm{m} \times 5.0 \mu \mathrm{m})$ (hydrolysis conditions for PAN support membrane: hydrolysis temperature: $60^{\circ} \mathrm{C}$, hydrolysis time: $15 \mathrm{~min}$; preparative conditions: only one PEI layer deposited, dynamic negative pressure: $-0.04 \mathrm{MPa}, 30 \mathrm{~min}$ filtration time, $0.25 \mathrm{wt} . \%$ aqueous PEI solution, $25^{\circ} \mathrm{C}$; pervaporation conditions: feed temperature $50{ }^{\circ} \mathrm{C}$, downstream pressure $100 \mathrm{~Pa}$ ). (d) Hollow fiber PEMM assembled by dynamic negative pressure LbL technique technique $(5.0 \mu \mathrm{m} \times 5.0 \mu \mathrm{m})$ (hydrolysis conditions for PAN support membrane: hydrolysis temperature: $60^{\circ} \mathrm{C}$, hydrolysis time: $15 \mathrm{~min}$; preparative conditions: 4.5 bilayers, dynamic negative pressure: $-0.04 \mathrm{MPa}$, $30 \mathrm{~min}$ filtration time, 0.05 wt.\% PAA aqueous solution, 0.25 wt.\% aqueous PEI solution, $25^{\circ} \mathrm{C}$; pervaporation conditions: feed temperature $50^{\circ} \mathrm{C}$, down-stream pressure $100 \mathrm{~Pa}$ ).

the pervaporation separation of ethanol/water system with the water content from 5 to $50 \mathrm{wt} . \%$. It was noted that the flux greatly increased from 290 to $7330 \mathrm{~g} /\left(\mathrm{m}^{2} \mathrm{~h}\right)$ while the separation factor decreased a little. However, the permeate always contained a water content at the range of 92.8-97.5 wt.\%. These suggested that the hollow fiber membranes obtained are really suitable for the separation of alcohol/water mixtures within a relatively wide concentration range.
In Table 3, the separation performances of different alcohol/water mixtures with the alcohols being $t$-butanol, and 2-propanol or ethanol are compared. Table 3 suggested that the selectivity increased with the increase in molecular size of alcohol. For example, in the case of pervaporation of $95 \mathrm{wt} . \% t$ butanol-water mixture, the separation factor and flux could reach 481 and $769 \mathrm{~g} /\left(\mathrm{m}^{2} \mathrm{~h}\right)\left(50^{\circ} \mathrm{C}\right)$, respectively. Obviously, the higher separation factor could be obtained when the strength of the hydro- 
Table 2

Water and ethanol partial fluxes under different feed temperature

\begin{tabular}{lccrr}
\hline & \multicolumn{5}{l}{ Feed temperature $\left({ }^{\circ} \mathrm{C}\right)$} \\
\cline { 2 - 5 } & \multicolumn{1}{c}{30} & 40 & \multicolumn{1}{c}{50} & \multicolumn{1}{c}{60} \\
\hline Water partial flux $\left(\mathrm{g} /\left(\mathrm{m}^{2} \mathrm{~h}\right)\right)$ & 78.2 & 147.2 & 269.1 & 326.4 \\
Ethanol partial flux $\left(\mathrm{g} /\left(\mathrm{m}^{2} \mathrm{~h}\right)\right)$ & 2.9 & 6.8 & 20.9 & 29.6 \\
\hline
\end{tabular}

Hydrolysis conditions for PAN support membrane: hydrolysis temperature: $60^{\circ} \mathrm{C}$ hydrolysis time: $15 \mathrm{~min}$; preparative conditions: 4.5 bilayers, dynamic negative pressure: $-0.04 \mathrm{MPa}, 30 \mathrm{~min}$ filtration time, $0.05 \mathrm{wt}$.\% PAA aqueous solution, $0.25 \mathrm{wt} . \%$ aqueous PEI solution, $25^{\circ} \mathrm{C}$; pervaporation conditions: feed temperature $50^{\circ} \mathrm{C}$, down-stream pressure $100 \mathrm{~Pa}$.

Table 3

Pervaporation performance of hollow fiber PEMMs for different alcohol/water feed mixture

\begin{tabular}{llll}
\hline Feed mixture & $\begin{array}{l}\text { Water content in } \\
\text { permeate }(\text { wt.\%) }\end{array}$ & $\begin{array}{l}\text { Separation } \\
\text { factor }(\alpha)\end{array}$ & $\begin{array}{l}\text { Total flux } \\
\left(\mathrm{g} /\left(\mathrm{m}^{2} \mathrm{~h}\right)\right)\end{array}$ \\
\hline 95 wt.\% ethanol-water & 92.8 & 245 & 290 \\
95 wt.\% 2-propanol-water & 94.4 & 320 & 600 \\
95 wt.\% $t$-butanol-water & 96.2 & 481 & 769 \\
\hline
\end{tabular}

Hydrolysis conditions for PAN support membrane: hydrolysis temperature: $60^{\circ} \mathrm{C}$, hydrolysis time: $15 \mathrm{~min}$; preparative conditions: 4.5 bilayers, dynamic negative pressure: $-0.04 \mathrm{MPa}, 30 \mathrm{~min}$ filtration time, $0.05 \mathrm{wt}$.\% PAA aqueous solution, $0.25 \mathrm{wt} . \%$ aqueous PEI solution, $25^{\circ} \mathrm{C}$; pervaporation conditions: feed temperature $50^{\circ} \mathrm{C}$, down-stream pressure $100 \mathrm{~Pa}$.

gen bonding decreases with increasing number of carbon atoms in the alcohol. This would facilitate water transport much more rapidly across the membrane. Therefore, the total flux increased. Meanwhile, hydrophobic alcohol molecules are more strongly rejected by the hydrophilic pores of the membrane.

\subsection{Membrane micrograph}

The top surface and overall cross-section morphologies of the layer-by-layer PEMMs of PAA/PEI were observed by SEM. Compared Fig. 7(a) and (c), it could be obviously observed that the pores were covered completely after depositing 4.5 bilayers by dynamic negative pressure LbL adsorption. In comparison with Fig. 7(b) and (c), the top layer covered with 4.5 bilayers was more uniform and much denser than that deposited with one PEI layer. This might be the reason that the selectivity of PEMMs obtained with 4.5 bilayers was relatively high. Meanwhile, it was found from Fig. 7(d) that hollow fiber composite membrane still kept its asymmetric structure and the outer layer remains porous. Obviously, the polyelectrolyte was only sealed the inner surface pores. In order to further understand the microtopographical changes on membrane surfaces, AFM tests were also performed. The threedimensional AFM images of support membranes before and after hydrolysis and the polyelectrolyte composite membranes are presented in Fig. 8. The values of mean roughness ( $\mathrm{Ra}$ ) was obtained based on $100.0 \mu \mathrm{m} \times 100.0 \mu \mathrm{m}$ scan area. It was noted that the top surfaces became smoother after hydrolysis with alkaline solution. For example, the Ra of the PAN membranes decreased from 1227.5 to $344.9 \mathrm{~nm}$ after $2 \mathrm{~N} \mathrm{NaOH}$ hydrolysis for $15 \mathrm{~min}$. This is because PAN with a certain content of carboxyl group is easily swollen when expose to aqueous medium. The swollen macromolecules then become more mobile to move towards the pores. This process decreases the pore size and makes the membrane surface smoother [18]. Significant changes in surface morphology were observed for PEMMs. It was noted that membrane surface roughness increased after depositing polyelectrolyte pairs. In the cases of PEMMs deposited one PEI layer and 4.5 bilayers, the Ra values of the hydrolyzed membranes were 370.6 and $817.0 \mathrm{~nm}$, respectively. The increase of membrane surface roughness might be attributed to the surface enrichment of polyelectrolyte pairs due to the electrostatic adsorption.

\section{Conclusions}

In this study, inner skin hollow fiber PEMMs was firstly successfully assembled by using a dynamic negative pressure LbL adsorption technique. The PEI/PAA, used as a model polyelectrolyte pair, was compulsorily deposited on the hydrolyzed hollow fiber PAN UF membrane. Under a negative pressure of $-0.04 \mathrm{MPa}$, the PEMMs obtained from 4.5 bilayers had a flux of 290 and a separation factor of 245 (feed solution $95 \mathrm{wt} . \%$ ethanol-water, $50^{\circ} \mathrm{C}$ ). The separation factor could further increase to 1338 while the permeate flux $120 \mathrm{~g} /\left(\mathrm{m}^{2} \mathrm{~h}\right)$ as the deposition increased to 6.5 bilayers. Further studies investigated the pervaporation performance within a wide feed temperature and feed concentration and the separation behavior of different alcohol/water mixtures. The experimental results indicated that the assembly of hollow fiber PEMMs with dynamic LbL technique is a feasible and promising method in the future study. As the inner skin hollow fiber pervaporation module could offer some advantages and it could easily be scaled up by using dynamic LbL process, this module and the dynamic LbL assembly method have great potential for industrial use.

\section{Acknowledgements}

This work was supported by the Key Project of the Natural Science Foundation of Beijing (no. 8071001), the Beijing NOVA Programme (no. 2006B13), Beijing Municipal Science and Technology Planning Project (no. Z0605010000091), the National Basic Research Program of China (no. 2003CB615701), and the Special Funding Project of the Beijing Municipal Commission of Education, P.R. China (no. 05005999200601).

\section{References}

[1] P. Shao, R.Y.M. Huang, Polymeric membrane pervaporation, J. Membr. Sci. 287 (2007) 162-179.

[2] W. Yuan, Y.S. Lin, W. Yang, Molecular sieving MFI-type zeolite membranes for pervaporation separation of xylene isomers, J. Am. Chem. Soc. 126 (2004) $4776-4777$.

[3] A. Sharma, S.P. Thampi, S.V. Suggala, P.K. Bhattacharya, Pervaporation from a dense membrane: roles of permeant membrane interactions, Kelvin effect, and membrane swelling, Langmuir 20 (2004) 4708-4714.

[4] L.Y. Jiang, T.S. Chung, R. Rajagopalan, Dehydration of alcohols by pervaporation through polyimide Matrimid ${ }^{\circledR}$ asymmetric hollow fibers with various modifications, Chem. Eng. Sci. 63 (2008) 204-216.

[5] R.X. Liu, X.Y. Qiao, T.S. Chung, Dual-layer P84/polyethersulfone hollow fibers for pervaporation dehydration of isopropanol, J. Membr. Sci. 294 (2007) 103-114.

[6] R.X. Liu, X.Y. Qiao, T.S. Chung, The development of high performance P84 copolyimide hollow fibers for pervaporation dehydration of isopropanol, Chem. Eng. Sci. 60 (2005) 6674-6686.

[7] Y.L. Liu, C.H. Yu, L.C. Ma, G.C. Lin, H.A. Tsai, J.Y. Lai, The effects of surface modifications on preparation and pervaporation dehydration performance of chitosan/polysulfone composite hollow-fiber membranes, J. Membr. Sci. 311 (1-2) (2008) 243-250.

[8] G. Decher, Fuzzy nanoassemblies: toward layered polymeric multicomposites, Science 277 (29) (1997) 1232-1237.

[9] L. Krasemann, A. Toutianoush, B. Tieke, Self-assembled polyelectrolyte multilayer membranes with highly improved pervaporation separation of ethanol/water mixtures, J. Membr. Sci. 181 (2001) 221-228.

[10] A. Toutianoush, B. Tieke, Pervaporation separation of alcohol/water mixtures using self-assembled polyelectrolyte multilayer membranes of high charge density, Mater. Sci. Eng. C 22 (2002) 459-463.

[11] A. Toutianoush, L. Krasemann, B. Tieke, Polyelectrolyte multilayer membranes for pervaporation separation of alcohol/water mixtures, Colloids Surf. A 198-200 (2002) 881-889.

[12] Z. Zhu, X. Feng, A. Penlidis, Self-assembled nano-structured polyelectrolyte composite membranes for pervaporation, Mater. Sci. Eng. C 26 (2006) 1-8.

[13] Y. Chen, F. Xiangli, W. Jin, N. Xu, Organic-inorganic composite pervaporation membranes prepared by self-assembly of polyelectrolyte multilayers on macroporous ceramic supports, J. Membr. Sci. 302 (2007) 78-86.

[14] G. Zhang, W. Gu, S. Ji, Z. Liu, Y. Peng, Z. Wang, Preparation of polyelectrolyte multilayer membranes by dynamic layer-by-layer process for pervaporation separation of alcohol/water mixtures, J. Membr. Sci. 280 (2006) 727-733. 
[15] G. Zhang, H. Yan, S. Ji, Z. Liu, Self-assembly of polyelectrolyte multilayer pervaporation membranes by a dynamic layer-by-layer technique on a hydrolyzed polyacrylonitrile ultrafiltration membrane, J. Membr. Sci. 292 (2007) 1-8.

[16] G. Zhang, X. Gao, S. Ji, Z. Liu, Electric field enhanced assembly of polyelectrolyte composite membranes, J. Membr. Sci. 307 (2008) 151-155.
[17] Z. Liu, G. Zhang, Y. Peng, S. Ji, The hollow fiber ultrafiltration membrane with inner skin and its application, Desalination 233 (2008) 55-63.

[18] Z.G. Wang, L.S. Wan, Z.K. Xu, Surface engineerings of polyacrylonitrile-based asymmetric membranes towards biomedical applications: An overview, J. Membr. Sci. 304 (2007) 8-23. 